fingers, which are manipulating letters of the alphabet on a specially designed board, which he he uses for writing. The tension on his hands and contorted fingers is such that all the veins are outlined dramatically, as if steep ridges in a micro landscape. The photograph brings us into his world: paralyzed, save the movement in his fingers. He has been forced by his condition to lie in bed for 20 years and, other than his caregivers, his sole connection to the outside world is his radio.

Cruz was profoundly moved by meeting this man, who instead of giving up, found a way of fighting back: he became a philosopher. "He dedicated his life to thinking, and so he overcame his situation, and it was a marvellous thing to see. A project like this is a constant education about life, about the human condition."

Hands are very important throughout Cruz's work, not surprisingly since they take over some of the functions of sight. In one picture, an elderly woman stands alone in front of a large plant of prickly pears. The sky is ominously dark. The feeling of starkness is accentuated by the mantle of thorns in the leaves of the cactus. The plant is untouchable. Is the

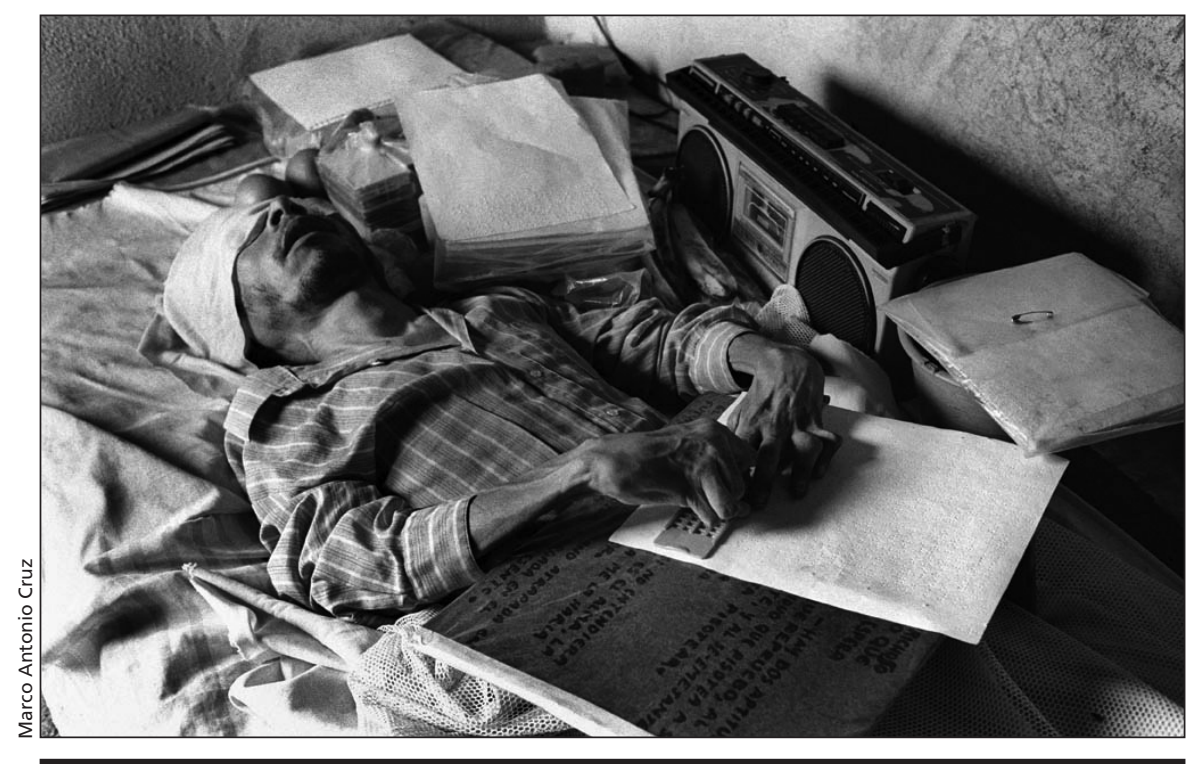

In 1970, at the age of 16, Porfirio Moreno Martinez developed juvenile rheumatoid arthritis and uveitis. After undergoing various treatments, including an unsuccessful operation, Martinez returned to his village, "took hold of the reins of his life" and became a philosopher. This photograph was taken on Mar. 14, 1998. woman also untouchable? Perhaps she bears a burden of infectious disease and ensuing stigma? She is facing the camera, but hides her face with her hands. In a momentary twist of irony, we are prevented from seeing her face, in the same way that she is prevented from seeing "our" face because of her blindness. This is how she holds onto her dignity: her gnarled hands become her face.

In another picture, a young boy is walking in a swimming pool, and we see his tiny hand pulled gently under the water by the much larger hand of an adult. The boy has just surfaced for air but is still holding his breath, his lips shut tightly, and his cheeks bulging. His eyes are fully open, yet we can plainly see that they are sightless. But he smiles with the same innocent pleasure of countless boys when they play with water. We smile back, for we feel a sense of solidarity. We are seeing blindness in new ways, more importantly, the humanity of people who are blind. Such is the power of Cruz's poignant work, which he hopes will help "to change the way we see, the way we think, the way we do things" with regard to blind people.

\section{Vincenzo Pietropaolo}

Photographer and author

Toronto, Ont.

Mr. Pietropaolo is the author of the upcoming book, Invisible No More, a photographic chronicle of people with intellectual disabilities (Rutgers, Spring 2010).

\title{
South Africa's womb
}

'T his is not a place anybody would want to have a baby," says the maternity unit director as he welcomed medical students to the ward. "We have no money to replace the beds. Things are falling apart. This place was not built to respect anyone. It was built with little regard for human decency or privacy. It was built to deliver."

Chris Hani Baragwanath Hospital, or
Bara, in Soweto, South Africa, sprawls over an area the size of a small town; reportedly it is the biggest hospital in the world. The maternity unit was designed with the understanding that only Black and Coloured people* would be born here. It's more than a decade after apartheid ended, but little has changed in the 50 years since Bara was built.

A hundred pregnant women are seen in the maternity unit every day.
On arrival, the women trade their clothes for thick cotton bags tied with a drawstring above their breasts. Women on the verge of delivery are transferred to the labour ward: an echoing hall lined with 30 cubicles where about 45 vaginal deliveries and

*These are the terms of apartheid race laws, which classified the population into White, Coloured, Indian, Asian and Bantu (or Black) groups. 
25 cesarean sections occur daily. The ward never stops.

Each morning a trolley circulates with sweet milky tea and brown loaves with butter, served on bright crockery emblazoned with "Baragwanath Hospital Labour Ward." Whiffs of tea and bread cut the stench of blood, feces, sweat, urine, amniotic fluid and disinfectant. There is almost no linen; the torn mattresses are putrid. Soon the cotton bags are soiled. The women lie naked, labouring in the heat. The midwives scream as much with the women as at them. One nurse told me that the place hasn't been quiet in 30 years.

Babies are placed immediately, bloody and raw on the mother's belly. I feel an affirmation of the organic nature of birthing. At home, this often remains hidden behind the sterility of a wellequipped hospital. Here it is impossible to clean birth of its essential and sometimes violent beauty. Life emerges in a fleshy torrent of sounds and smells.

One day a woman who had not received any prenatal care arrives at the hospital in labour. She is HIV-positive and her baby is breech, so she is placed third from the top of the cesarean list. Suddenly from her cubicle she screams, "Feet!" As she delivers the knees, a registrar prepares for an episiotomy. But the scissors are blunt and the midwives can't find any others. Though absolutely nothing worked properly, everything went perfectly. The baby delivered breech. There was no tear. Mother and child went home the next day.

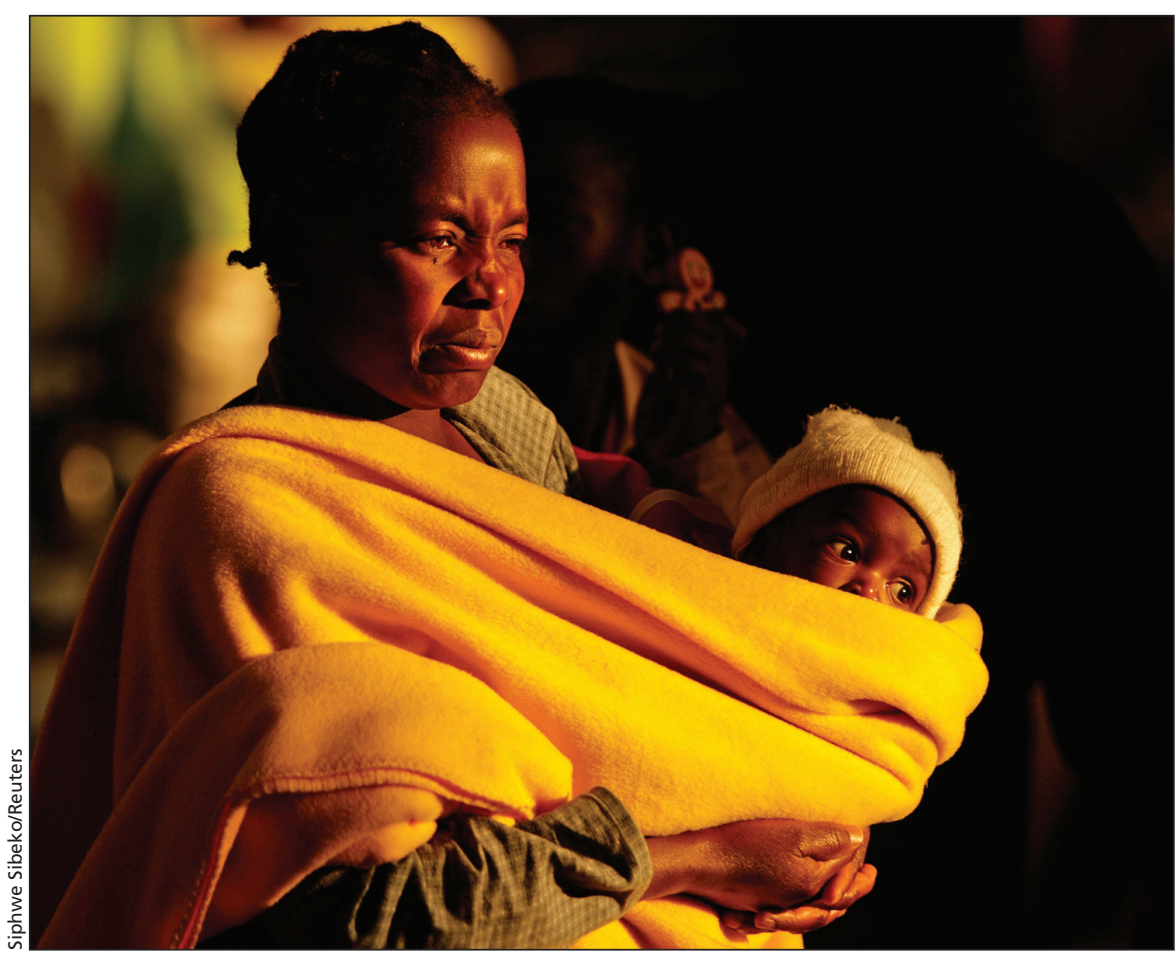

a powerful postapartheid dynamic at play between the very poor black patients, the middle class of black nurses and midwives, and the predominantly white physicians and surgeons. Many nurses display resentment toward the patients. Pejorative slurs escalate to insults. Insults can escalate to the occasional slap or perineum repairs without proper anesthetic. The dark past, the violent present and all the pains and contradictions of postapartheid South Africa flow as brilliant and bloody through this hospital, its patients and its

\section{"In a place like this, somehow the patient becomes the enemy."}

One afternoon I volunteer to assist with the repair of a c-section done at a distant rural hospital. The woman had been left packed in hospital for days before transfer to Bara. Unspeakable damage had been done to muscle, bladder, ureters and bowel. Other than patch things together as best as possible, what else is there to do?

Staff at Bara are almost never uncaring, but in the most harrowing cases residual race and class struggles emerge between the patients and staff. There is staff, as through the births themselves.

"Your responsibility while you are here is to try to be decent," explained the director in his introduction to the students. "Many of the nurses and sisters are burned out. They're just too used to this place. The worst thing you can do is get too used to it."

"Medicine just isn't what you expected it to be," sighed a local intern. He paused as a nurse rolled past singing a Zulu lullaby for a crib full of 6 newborns. "In a place like this, some- how the patient becomes the enemy."

There is a perennial lack of medical supplies in the storerooms, pharmaceutical cabinets and diagnostics lab, so Bara has little to offer beyond its staff, and their remarkable skills and expertise. Six thousand doctors and nurses work at Bara. Hospital administrators say they need about 1000 more. For every 1000 babies born here, 30 are stillborn. Thirteen more die within a few hours of birth. In Canada the stillbirth rate is just under 7 per 1000 births.

I sat in the labour ward one night as it shook through a highveld Johannesburg lightning storm. The roof and windows leaked into buckets. Sheets of rain pounded on the tin roofing. Lightning flashes illuminated the entire sky. I closed my eyes and listened to the cacophony of rain, thunder, and birthing women in unison and felt I had entered the writhing, moaning, centre of creation itself.

\section{Aaron Orkin BArtSc MD}

Family medicine resident

Northern Ontario School of Medicine Thunder Bay, Ont.

As a clerk, Dr. Orkin did an elective in obstetrics in South Africa for a month in 2007. He is now pursuing graduate studies in the history and philosophy of medicine. 